\title{
Synthesizing super-hydrophobic ground granulated blast furnace slag to enhance the transport property of lightweight aggregate concrete
}

Citation for published version (APA):

Qu, Z. Y., \& Yu, Q. L. (2018). Synthesizing super-hydrophobic ground granulated blast furnace slag to enhance the transport property of lightweight aggregate concrete. Construction and Building Materials, 191, 176-186. https://doi.org/10.1016/j.conbuildmat.2018.10.018

Document license:

TAVERNE

DOI:

10.1016/j.conbuildmat.2018.10.018

Document status and date:

Published: 10/12/2018

Document Version:

Publisher's PDF, also known as Version of Record (includes final page, issue and volume numbers)

\section{Please check the document version of this publication:}

- A submitted manuscript is the version of the article upon submission and before peer-review. There can be important differences between the submitted version and the official published version of record. People interested in the research are advised to contact the author for the final version of the publication, or visit the $\mathrm{DOI}$ to the publisher's website.

- The final author version and the galley proof are versions of the publication after peer review.

- The final published version features the final layout of the paper including the volume, issue and page numbers.

Link to publication

\footnotetext{
General rights

- You may freely distribute the URL identifying the publication in the public portal. follow below link for the End User Agreement:

www.tue.nl/taverne

Take down policy

If you believe that this document breaches copyright please contact us at:

openaccess@tue.nl

providing details and we will investigate your claim.
}

Copyright and moral rights for the publications made accessible in the public portal are retained by the authors and/or other copyright owners and it is a condition of accessing publications that users recognise and abide by the legal requirements associated with these rights.

- Users may download and print one copy of any publication from the public portal for the purpose of private study or research.

- You may not further distribute the material or use it for any profit-making activity or commercial gain

If the publication is distributed under the terms of Article 25fa of the Dutch Copyright Act, indicated by the "Taverne" license above, please 


\title{
Synthesizing super-hydrophobic ground granulated blast furnace slag to enhance the transport property of lightweight aggregate concrete
}

\author{
Z.Y. Qu, Q.L. Yu* \\ Department of the Built Environment, Eindhoven University of Technology, P.O. Box 513, 5600 MB Eindhoven, The Netherlands
}

\section{H I G H L I G H T S}

- A super-hydrophobic GGBS is prepared through a ball milling method.

- Optimum synthesis conditions to prepare super-hydrophobic GGBS are explored.

- Applying super-hydrophobic GGBS to lightweight concrete makes it hydrophobic.

- Correlation between the super-hydrophobic GGBS and concrete microstructure is studied.

- Applying super-hydrophobic GGBS to lightweight concrete enhances transport properties.

\section{A R T I C L E I N F O}

\section{Article history:}

Received 18 April 2018

Received in revised form 21 September 2018

Accepted 3 October 2018

\section{Keywords:}

Ground granulated blast furnace slag

Physical carrier

Stearic acid

Hydrophobicity

Lightweight aggregates concrete

Transport properties

\begin{abstract}
A B S T R A C T
This paper studies the feasibility of synthesising super-hydrophobic ground granulated blast furnace slag (GGBS) as water-resisting admixture in lightweight aggregate concrete. The super-hydrophobic GGBS was produced through a ball milling method using the low cost stearic acid. Results show that optimum synthesis involves dry milling stearic acid for $0.5 \mathrm{~h}$ with the dosage of $1 \mathrm{wt} \%$, producing a superhydrophobic GGBS that shows a water contact angle of $155.7^{\circ}$. The morphology, crystalline structure, functional group and chemical state of the atoms were investigated employing SEM, XRD, FTIR and XPS. TEM analysis shows that the thickness of the stearic acid coating is $7.1 \mathrm{~nm}$, confirming the theoretically calculated value. Lightweight aggregate concretes are designed applying an optimized particle packing theory and the effects of super-hydrophobic GGBS on cement hydration, workability, fresh density, strength and transport properties of the concrete are evaluated. Moreover, the relationship between the super-hydrophobic GGBS and the transport properties related performance of the lightweight concrete is discussed. With the addition of the super-hydrophobic GGBS, the capillary water absorption and long-term chloride penetration depth of the LWAC reduce up to about $90 \%$.
\end{abstract}

(c) 2018 Elsevier Ltd. All rights reserved.

\section{Introduction}

The application of lightweight aggregate concrete (LWAC) as both structural and non-structural material has gained much attention [1], and extensive investigations have been carried out on LWAC due to its superior properties like low density, excellent thermal properties and good fire resistance property $[2,3]$. However, caused by the porous lightweight aggregates (LWA), LWAC has the potential to show high permeability, especially compared to normal density concretes $[4,5]$. Although the application of lightweight aggregates with relatively closed pores can help to increase the resistance to fluids transport, the rather smooth surface of such aggregates leads to a potential decrease of mechanical

\footnotetext{
* Corresponding author.

E-mail address: q.yu@bwk.tue.nl (Q.L. Yu).
}

strength and the defects on the surface of such aggregates remain passages for the fluids to penetrate [3,6]. Therefore, additional treatments are often needed to enhance the transport properties of LWAC. Nano-materials such as nano-silica have been investigated to refine microstructure of LWAC for better durability performance $[5,7,8]$. Nevertheless, issues such as the limit to reduce porosity and large water demand due to the high specific surface area, in addition to the high cost, still exist $[9,10]$.

Hydrophobic modification is an efficient way to improve the transport performance by preventing water from penetrating into concrete structures [11]. Most existing strategies for hydrophobic modification for concrete apply extra surface treatment or hydrophobic ingredients in concrete matrix $[11,12]$. Because of the ease of dispersion and preparation, silane, siloxane or a mixture of these two components are most commonly used for hydrophobic modification for concrete at ambient conditions [13]. However, 
because of the relatively high price, their large utilization in concrete is still practically difficult $[11,14]$. Furthermore, premature cracks can occur as a result of shrinkage of cementitious materials at early age, making the concrete more vulnerable to the ingress of potentially aggressive species, which will significantly decrease the water repellent effect of the surface modification $[11,12]$. Therefore, the bulk volume modification is a more preferable manner to increase the concrete durability [12].

Compared with the silane and siloxane, saturated fatty acid is much cheaper and has already been used to prepare hydrophobic materials $[15,16]$. However, a pre-treatment step, such as water bath heating is needed to disperse it as it is in solid state at room temperature and thus it is difficult to get well dispersed during the application process $[17,18]$. Different from the soft chemical method mentioned above, mechanical approach such as ball milling has also been applied to prepare the super-hydrophobic powders, by which the mechanical coating of hydrophobic agent on the target powders occurs $[16,19]$. During the milling process, the added chemical agent will be coated on the surface of the powders, consequently endowing them with hydrophobic property. The hydrophobic performance of the powders prepared by this method is dependent on a number of parameters, including such as the nature and amount of the powders and surfactant, ball to solid ratio, milling speed and time [20,21]. Unlike the soft chemical method in which certain parameters crucially affect the preparation efficiency, no significant issues exist in mechanical approaches [20]. Comparing with the soft chemical method with which the target powders are added to the solution of surfactant agent, physical coating method like ball milling sometimes shows coating defects, especially when the powders present irregular shape [21]. The uncoated parts of the target powder will decrease the hydrophobicity. Declan et al. found that the defects of the coating cause the strength decrease of the polymer composite (high density polyethylene based), attributed to the decrease of interfacial adhesion between polyethylene and stearic acid modified peat ash powders [22]. Li et al. reported that high rotation speed and long ball milling time are necessary in order to achieve a perfect coating with ball milling method [23]. Spathi et al. prepared super-hydrophobic powder applying paper sludge ash as the primary material and applied it in concrete to improve the durability performance [16]. However, the preparation process needs long time $(8 \mathrm{~h})$ and high stearic acid addition ( $4 \mathrm{wt} \%$ ). This may be attributed to the porous structure with significantly high pore volume of the paper sludge ash which absorbs more surfactant and more time is therefore needed to react. Therefore, powders with smaller porosity are desired. Liu et al. successfully prepared hydrophobic stearic acid coated zirconia powders and the BET surface area of $\mathrm{ZrO}_{2}$ is $8.21 \mathrm{~m}^{2} / \mathrm{g}$ [24]. With a stearic acid addition of $0.5 \mathrm{wt} \%$, a coating with a very thin layer of about $0.5-0.8 \mathrm{~nm}$ can be achieved. Nevertheless, up to now no research has been reported on dealing with a powder with reactivity potential to be a bulk hydrophobic modification agent.

Blast furnace slag is an industrial by-product resulting from ion production, and it consists primarily of silicates, and aluminate and calcium [25]. In order to broaden the application range, the original granules with large-sizes are always grounded to fine particles, known as ground granulated blast furnace slag [25]. The minerals contain melilite, merwinite, dicalcium silicate, wollastonite, anorthite, monticellite, etc. $[25,26]$. The excellent cementitious property of blast furnace slag has made it a very popular supplementary cementitious material for concrete production [26-28]. In this study, a reactive GGBS powder is used as a carrier of stearic acid, employing a mechanical coating method. It shall be noted that the potential impact coating of GGBS will help to remain the cementitious property of GGBS, which is desired. The optimal synthesis conditions in terms of hydrophobicity are evaluated.
The acquired GGBS is assessed by X-ray diffraction (XRD), Fourier transform infrared (FTIR), thermogravimetry analysis (TGA), BET specific surface area and transmission electron microscopy (TEM). The hydrophobic performance is evaluated by the water contact angle measurement. Subsequently the synthesized superhydrophobic powder is applied to lightweight aggregates concrete to enhance its resistance to fluids transport. One type of natural expanded silicate material is used here as the lightweight aggregates [29]. The influence of the super-hydrophobic slag (H-GGBS) on cement hydration at the early age, flowability, mechanical property, microstructure and hydrophobicity of the lightweight concrete is investigated. More importantly, the developed lightweight concrete is investigated in terms of capillary water absorption and long term natural chloride diffusion concerning the durability aspects and the effect of the super-hydrophobic slag powder is discussed.

\section{Experiment}

\subsection{Materials and mix design of LWAC}

\subsubsection{Materials}

The ground granulated blast furnace slag (GGBS) was supplied by ENCI B.V. (the Netherlands). The elemental composition of the GGBS is determined by X-ray fluorescence, as: $34.61 \% \mathrm{SiO}_{2}$, $37.63 \% \mathrm{CaO}, 13.26 \% \mathrm{Al}_{2} \mathrm{O}_{3}, 9.94 \% \mathrm{MgO}, 0.47 \% \mathrm{Fe}_{2} \mathrm{O}_{3}, 1.24 \% \mathrm{SO}_{3}$, $0.47 \% \mathrm{~K}_{2} \mathrm{O}, 0.98 \% \mathrm{TiO}_{2}, 0.01 \% \mathrm{Cl}$, and $0.46 \%$ L.O.I. The SEM morphology of the raw GGBS and milled GGBS is investigated by a Phenom Pro analyser and are shown in Fig. 1 (a) and (b). CEM III/A $52.5 \mathrm{~N}$ (supplied by ENCI B.V., The Netherlands) was used, considering both the sustainability and durability performance by the contained slag.

Four size fractions of natural expanded silicate material were used as lightweight aggregates which are supplied by ROTEC $\mathrm{GmbH} \&$ Co. KG Rohstoff-Technik (Germany), including 0.09$0.3 \mathrm{~mm}, 0.5-1.0 \mathrm{~mm}, 1.0-2.0 \mathrm{~mm}$ and $2.0-4.0 \mathrm{~mm}$ (see Fig. 2). The aggregates have a very low thermal conductivity of about $0.08 \mathrm{~W} /\left(\mathrm{m} \cdot \mathrm{K}\right.$ ) with a crushing strength from $12 \mathrm{~N} / \mathrm{mm}^{2}$ (fraction $2-4 \mathrm{~mm}$ ) to $22 \mathrm{~N} / \mathrm{mm}^{2}$ (fraction $0.09-0.3 \mathrm{~mm}$ ). A polycarboxylate ether based superplasticizer (SP) was used to adjust the flowability of the designed concrete to the desired value. A stearic acid (reagent grade, 95\%) was used to synthesize the superhydrophobic GGBS.

\subsubsection{Synthesis of the super-hydrophobic slag}

Ball milling method was used to prepare the hydrophobic GGBS powder with stearic acid, using a porcelain ball mill pot (Fritsch; Pulverisette 5) loaded with 20 alumina milling balls ( $d=20 \mathrm{~mm}$ ) inside. The stearic acid and GGBS were added together into the milling pot. Different experimental conditions including the milling time, speed and stearic acid dosage were experimented to achieve the optimum performance, in terms of water-contact angle that is determined with a pressed pellet. The influences of rotation speed and time to the hydrophobic performance of GGBS were investigated. The influence of stearic acid dosage on the hydrophobicity of the GGBS powders was studied by using $0.5,1$, 2 and $4 \mathrm{wt} \%$ additions of stearic acid with all other processing variables kept constant.

\subsubsection{Mix proportions of the LWAC}

As aforementioned, the bulk treatment was carried out by replacing CEM III/A $52.5 \mathrm{~N}$ with the S-GGBS. Reference samples were prepared for comparing the effect of S-GGBS incorporation on the performance of the designed LWAC. The modified Andreasen and Andersen model was applied for determining the mix pro- 

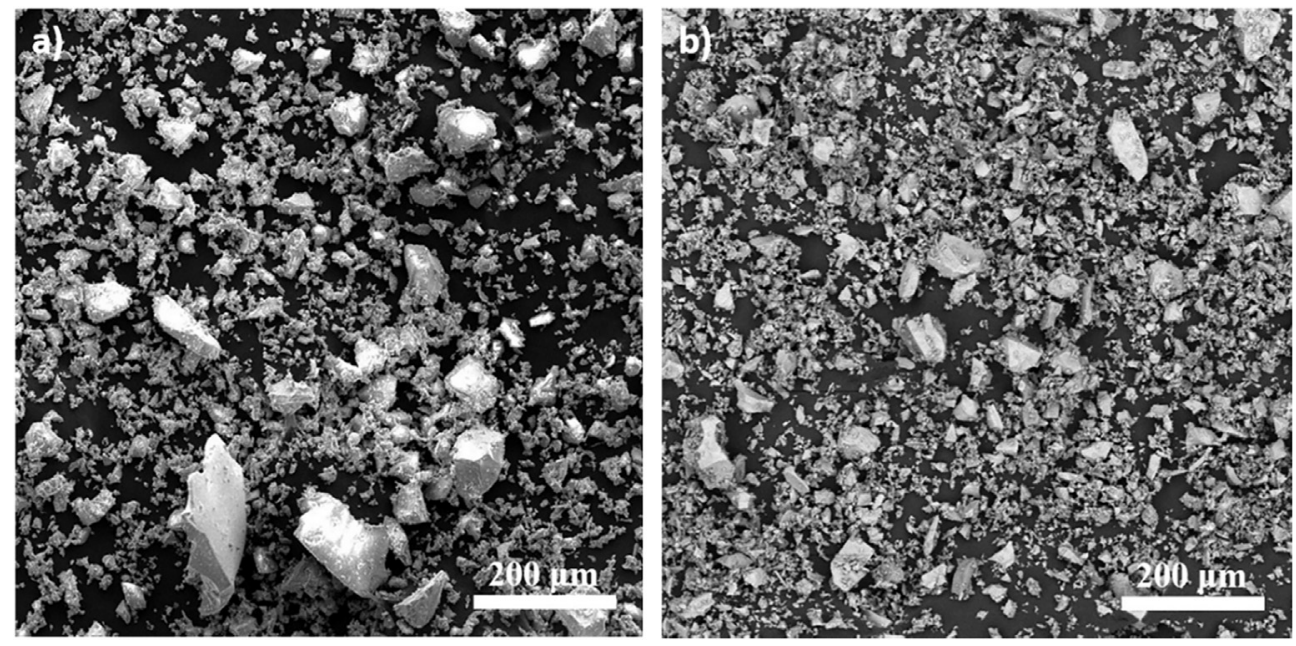

Fig. 1. SEM picture of (a) the GGBS, and (b) milled GGBS.

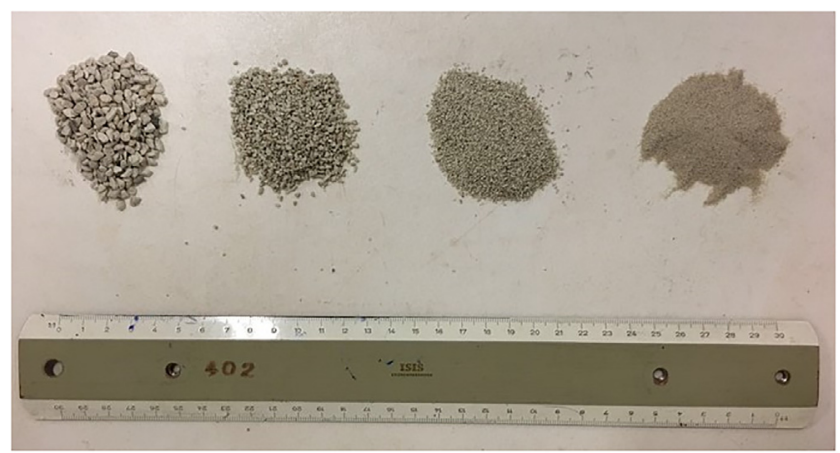

Fig. 2. Picture of the used lightweight aggregates.

portions of the lightweight aggregates concrete. Detailed mix design methodology has been investigated and can be found elsewhere $[1,5,30]$. Table 1 summarizes the mix proportions of the lightweight concrete. The prepared hydrophobic GGBS (H-GGBS) powder was applied to replace the cement with different mass ratios of 5\% - 20\% (denoting M5 - M20 accordingly), respectively, in the concrete mix.

\subsection{Experimental}

\subsubsection{Characterization of raw and treated slag}

The static water contact angle was determined employing a DataPhysics SCA20 (DataPhysics Germany) at the ambient temperature. Water with the volume of $5 \mu$ l was dripped on the surface of a pressed disc sample of the S-GGBS, which was prepared by putting $6 \mathrm{~g}$ of powders in a $40 \mathrm{~mm}$ diameter press set and then pressed with a load of $4 \mathrm{kN}$ for about $1 \mathrm{~min}$. To determine the water contact angle of lightweight concrete, a piece of plateshape specimen of about $3 \mathrm{~cm}$ in width is extracted from the hardened lightweight concrete for the measurement. The XRD analysis was performed to the S-GGBS and reference GGBS, scanning from $5^{\circ}$ to $65^{\circ}(2 \theta)$ with a step $0.02^{\circ}$ and $0.2 \mathrm{~s} / \mathrm{step}$ interval (Bruker D8 advance powder X-ray diffractometer with a $\mathrm{Cu}$ tube $(20 \mathrm{kV}$, $10 \mathrm{~mA})$ ). The FT-IR spectra of the raw GGBS and hydrophobic treated GGBS were collected from 4000 to $400 \mathrm{~cm}^{-1}$ with a resolution of $4 \mathrm{~cm}^{-1}$ using a PerkinElmer FrontierTM MIR/FIR Spectrometer. The XPS spectra of the S-GGBS and raw GGBS were acquired using an X-ray photoelectron spectrometer (ThermoScientific K-Alpha) and the spectra were fitted by CasaXPS software. Thermogravimetric and differential thermal analyses (TGA/DTA) were carried out with a STA 449 F1 Jupiter ${ }^{\circledR}$ analyser and the data were recorded with alumina as an inert reference. Transmission electron microscopy image was taken with a JEOL JEM-100CX instrument to determine the thickness of the stearic acid coating on the GGBS.

\subsubsection{Hydration kinetics}

The influence of the S-GGBS on the cement hydration kinetics was assessed by employing an TAM Air isothermal calorimeter. The tests were carried out for $80 \mathrm{~h}$ at $20^{\circ} \mathrm{C}$. The results were normalized by the mass of solid powders.

\subsubsection{Fresh behaviour of the LWAC}

The workability of the designed lightweight aggregate concrete was determined using the flow table tests according to EN 123505:2009 [31]. The fresh density was determined according to EN 12350-6:2009.

Table 1

Mix proportions of the lightweight concrete $\left(\mathrm{kg} / \mathrm{m}^{3}\right)$.

\begin{tabular}{|c|c|c|c|c|c|}
\hline Materials & M0 & M5 & M10 & M15 & M20 \\
\hline CEM III/A $52.5 \mathrm{~N}$ & 429 & 407.55 & 386.1 & 364.65 & 343.2 \\
\hline H-GGBS & 0 & 21.45 & 42.9 & 64.35 & 85.8 \\
\hline Class F Fly ash & 45 & 45 & 45 & 45 & 45 \\
\hline Limestone powder & 59 & 59 & 59 & 59 & 59 \\
\hline LWA $0.09-0.3 \mathrm{~mm}$ & 119.2 & 119.2 & 119.2 & 119.2 & 119.2 \\
\hline LWA $0.5-1 \mathrm{~mm}$ & 74.2 & 74.2 & 74.2 & 74.2 & 74.2 \\
\hline LWA $1-2 \mathrm{~mm}$ & 83.4 & 83.4 & 83.4 & 83.4 & 83.4 \\
\hline LWA 2-4 mm & 96.7 & 96.7 & 96.7 & 96.7 & 96.7 \\
\hline Water & 187 & 187 & 187 & 187 & 187 \\
\hline Superplasticizer & 5.15 & 5.15 & 5.15 & 5.15 & 5.15 \\
\hline
\end{tabular}




\subsubsection{Mechanical property of the LWAC}

The fresh lightweight aggregate concrete was cast in moulds of $40 \mathrm{~mm} \times 40 \mathrm{~mm} \times 160 \mathrm{~mm}^{3}$. The samples were demoulded after $24 \mathrm{~h}$ and then cured at $100 \% \mathrm{RH}$ under room temperature of about $21 \pm 1^{\circ} \mathrm{C}$. The flexural and compressive strengths of the specimens were tested at the age of 7 and 28 days respectively according to EN 196-1 [32].

\subsubsection{Capillary water absorption of the LWAC}

The capillary water absorption of the LWAC was determined according to EN 480-5 [33]. The experiments started by storing the samples vertically in a chamber with a $\mathrm{RH}$ of about $65 \pm 5 \%$ at room temperature $\left(20 \pm 1^{\circ} \mathrm{C}\right)$ after curing the samples for 28 days. The samples was exposed toe water with an immersion depth of about $3 \mathrm{~mm}$ for a duration of 43 days and the mass of the samples was periodically measured during the experiment.

\subsubsection{Chloride penetration depth of the LWAC}

The chloride penetration depth test was carried out to the samples at the curing age of 28 days according to NT Build 443 [34]. Cylindrical samples were immersed in a salt solution with a concentration of $2.84 \mathrm{M}$ for 63 days. The penetration depth was determined after the experiment by using a $0.1 \mathrm{M} \mathrm{AgNO}_{3}$ as a chloride colorimetric indicator to the split samples.

\section{Results and discussions}

\subsection{Characterization}

\subsubsection{Optimal synthesis conditions}

The influences of milling conditions on the hydrophobicity are depicted in Fig. 3. It is demonstrated that at $200 \mathrm{rpm}$ rotation speed, $30 \mathrm{~min}$ is the optimal duration for the preparation of the super-hydrophobic powder (Fig. 3a). At a short mixing duration (i.e. $10 \mathrm{~min}$ ), the stearic acid cannot be dispersed efficiently. When the rotation time is too long (i.e. $60 \mathrm{~min}$ ), the increased collision between the GGBS and the milling ball grinding media would induce higher shear forces, resulting in the molecular chains of the surfactant with a shorter length by cutting effect. Consequently, the steric hindrance provided by the preferentially adsorbed molecules on the particle surface is reduced [17], which results in clusters on the milling ball, in turn a decreased dispersion efficiency. It is also seen that $1 \%$ stearic acid addition is the optimum amount. This is because at a low addition amount
$(0.5 \%)$, the stearic acid is not able to coat the total surface of the GGBS. When increasing the stearic acid dosage larger than $1 \%$, the potentially produced agglomeration or multi-layer (even) of stearic acid on the surface of GGBS which would decrease the water contact angle [19].

The influence of rotation speed is investigated, as shown in Fig. 3b. There is an increase in hydrophobicity from a water contact angle of $127.4^{\circ}$ at $50 \mathrm{rpm}$ to $155.9^{\circ}$ at $100 \mathrm{rpm}$. Then, the hydrophobicity of the GGBS keeps almost the same when further increasing the rotation speed. According to the definition of super hydrophobicity, the powders prepared at $100 \mathrm{rpm}, 150 \mathrm{rpm}$ and $200 \mathrm{rpm}$ can all be defined as super-hydrophobic slag powder [35]. It is concluded that a rotation speed of $100 \mathrm{rpm}$ provides the optimal outcome. In this study, the super-hydrophobic powder for application in the lightweight concrete is therefore prepared under the optimum condition, i.e. $1 \%$ stearic acid addition at $100 \mathrm{rpm}$ rotation speed for milling 30 mins. Comparing with the preparation process in [16], the time consumption here is much less while $8 \mathrm{~h}$ were needed to prepare super-hydrophobic paper sludge ash. This can be attributed to the nature of the GGBS which possesses rather non-porous structure and less function group which can react with the stearic acid on the surface.

\subsubsection{Xrd}

The XRD patterns of the raw and coated GGBS are shown in Fig. 4. No crystalline phase is observed in the untreated slags. A broad peak near $30^{\circ}$ is seen, attributed to incomplete crystallization of silicate minerals [25]. The stearic acid coated slag presents a similar XRD pattern and no new diffraction peaks appear after the addition of stearic acid. It indicates that the crystalline structure of the phases in GGBS is not changed by the addition of stearic acid, which is in line with $[17,25]$. This is because that in the dry milling process, the stearic acid plays a role as a modification agent on powder surface.

As no decrease is found in peak intensity as well as broadening in full width at half maximum in the XRD patterns, it can be concluded that ball milling does not disperse the stearic acid to cover the whole surface of the GGBS. This can be attributed to the morphology of the slag which presents an irregular shape and faceted surface morphology as shown in Fig. 1. Therefore, after the milling, the GGBS plays a role of carrier of the stearic acid, while the reactivity of the slag will remain and still can be used as a reactive raw phase for hydration.
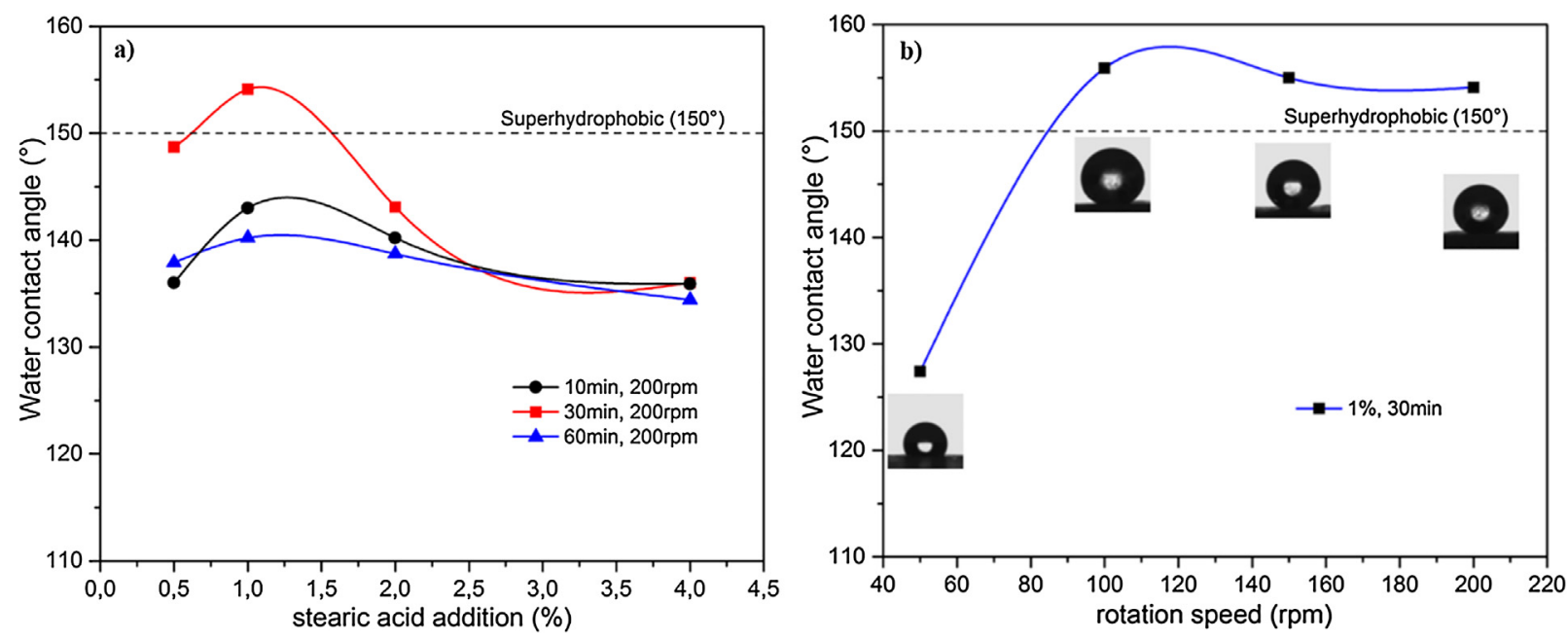

Fig. 3. The optimum milling process to prepare the H-GGBS powders: (a) milling time and stearic acid addition amount; (b) rotation speed. 


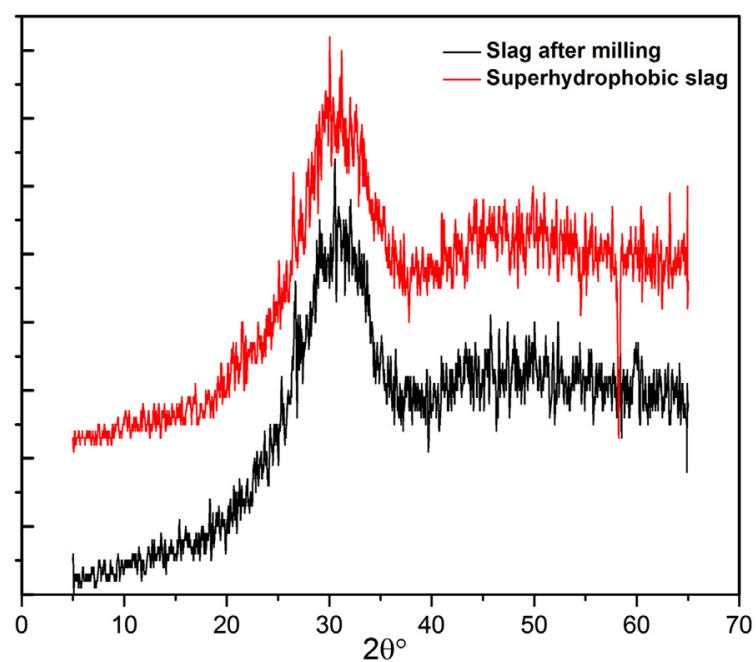

Fig. 4. XRD spectra of the milling slag and coated slag.

\subsubsection{Xps}

The XPS spectra for the original slag and super-hydrophobic slag are shown in Fig. $5 a$ and b. It is shown that the peak area of major elements decreased with different degrees except that of carbon increased by $15.88 \%$. This can be attributed to the long chain of $\mathrm{CH} 2$ in the stearic acid. The changes of $\mathrm{C} 1 \mathrm{~s}$ photoelectron spectra are useful indicators of the surface transformations that occur before and after stearic acid treatment. One clearly resolved peak at $285 \mathrm{eV}$ can be found in both raw GGBS and S-GGBS. This main peak reflects $\mathrm{C}-\mathrm{C}$ bonds in $\mathrm{C}_{\mathrm{x}} \mathrm{H}_{\mathrm{x}}$ hydrocarbons [37]. The lower intensity peak at $289.7 \mathrm{eV}$ can be attributed to $\mathrm{CO}_{3}^{2-}$ functional group as GGBS contains carbonate while the peaks at $286.7 \mathrm{eV}$ and $288.1 \mathrm{eV}$ can be attributed to $\mathrm{C}-\mathrm{O}$ and $\mathrm{O}-\mathrm{C}-\mathrm{O}$ functional groups, respectively, indicating hydrocarbon impurities [31].

It is clear that the photoelectron peak of C-C of superhydrophobic slag (as shown in Fig. 5b) amplified when comparing with the reference GGBS (Fig. 5a), while the intensity of the other three lower peaks decreased. This can be explained by the stearic acid coated on the GGBS. Stearic acid contains a long chain of $\mathrm{CH}_{2}$ and $\mathrm{CH}_{3}$ that adds extra $\mathrm{C}-\mathrm{C}$ bonds because of the ethyl group that could explain the intensity increase of the C-C bond [36]. As there is no evidence for potential reaction group such as $-\mathrm{OH}$, it could be concluded that the stearic acid molecule was physically absorbed on the surface of the GGBS. This physical binding feature is beneficial to prepare hydrophobic concrete as the stearic acid is easier to escape from the slag and enters the pore solution of concrete. This will result in better dispersion, consequently enhancing the hydrophobic property of the developed concrete. The physical binding property can also be used to explain the high efficiency to prepare the super-hydrophobic slag as less time and energy is needed, compared with the chemical process.

\subsubsection{Ftir}

The FTIR spectra of the raw and the treated GGBS are shown in Fig. 6 . The raw slag shows a broad band centred at approximate $891 \mathrm{~cm}^{-1}$ and $674 \mathrm{~cm}^{-1}$ which can be assigned to the vibration of $\mathrm{Si}-\mathrm{O}$ bands in the $\mathrm{SiO}_{4}$ groups and $\mathrm{Al}-\mathrm{O}$ bands in the $\mathrm{AlO}_{4}$ groups, respectively. While the weak bands around $1455 \mathrm{~cm}^{-1}, 871 \mathrm{~cm}^{-1}$ and $717 \mathrm{~cm}^{-1}$ are the vibration of $v_{3}\left[\mathrm{CO}_{3}^{2-}\right], v_{2}\left[\mathrm{CO}_{3}^{2-}\right]$ and $v_{4}\left[\mathrm{CO}_{3}^{2-}\right]$, respectively. In the spectra of coated slag, the bands at $2919 \mathrm{~cm}^{-1}$ and $2851 \mathrm{~cm}^{-1}$ could be related to $\mathrm{C}-\mathrm{H}$ bonds asymmetric stretching vibration and symmetrical stretching vibration, respectively, which helps to identify the $-\mathrm{CH}_{2}$ - single bond group. The $-\mathrm{CH}_{3}-$ group was identified by asymmetric stretching vibrations of $\mathrm{C}-\mathrm{H}$ bonds which occur generally at $2957 \mathrm{~cm}^{-1}$.

It should be pointed out that no group that has a potential to react with stearic acid can be found on the surface of slag such as $-\mathrm{O}-\mathrm{H}$ - bond. This confirms that the coating process is a physical process as no reaction product and no potential reaction agent are found. This explains that less stearic acid amount is needed to achieve the super-hydrophobic function. This is further confirmed by the short preparation time of the super-hydrophobic slag.

\subsubsection{Thickness of the stearic acid coating}

Thermogravimetric analysis was used to quantify the coating of stearic acid on the surface of GGBS as it decomposes at certain temperature. The mass loss of coated GGBS sample in the range of 200$450{ }^{\circ} \mathrm{C}$ is attributed to the oxygenolysis of stearic acid on the surface of the super-hydrophobic slag [17], as shown in Fig. 7a. The weight loss of super-hydrophobic slag is $1.2 \%$ higher than the milling slag that is in line with the theoretical value (1\%), confirming again the physically coated stearic acid on the surface of GGBS.

The difference of the mass loss can be used to calculate the theoretical thickness of the stearic acid coated on the superhydrophobic slag. According to [17], the theoretical thickness of

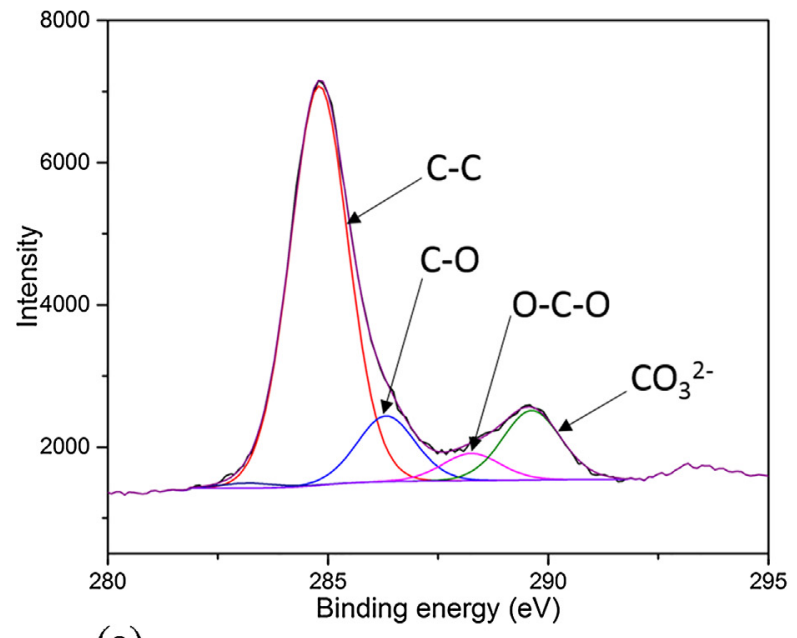

(a)

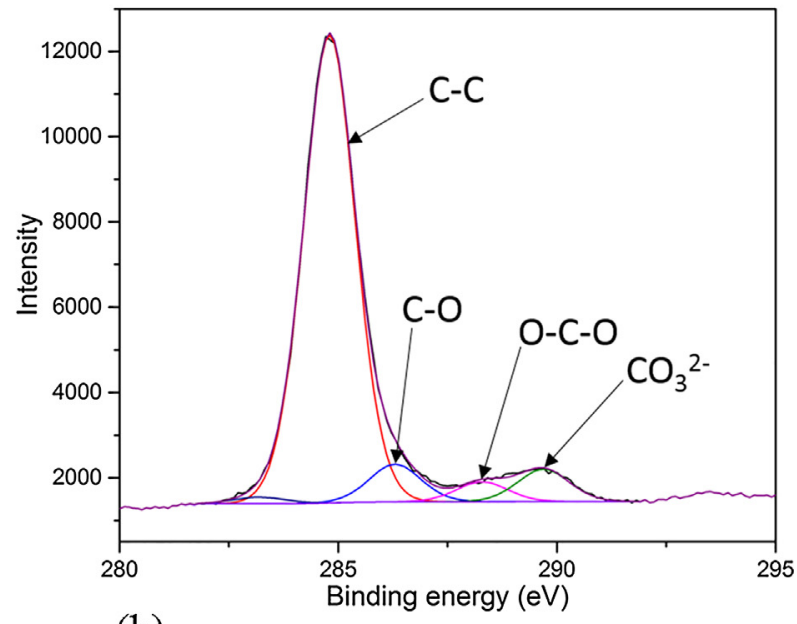

(b)

Fig. 5. C 1 s XPS spectra for: (a) the slag and (b) super-hydrophobic slag with peak fitted. 


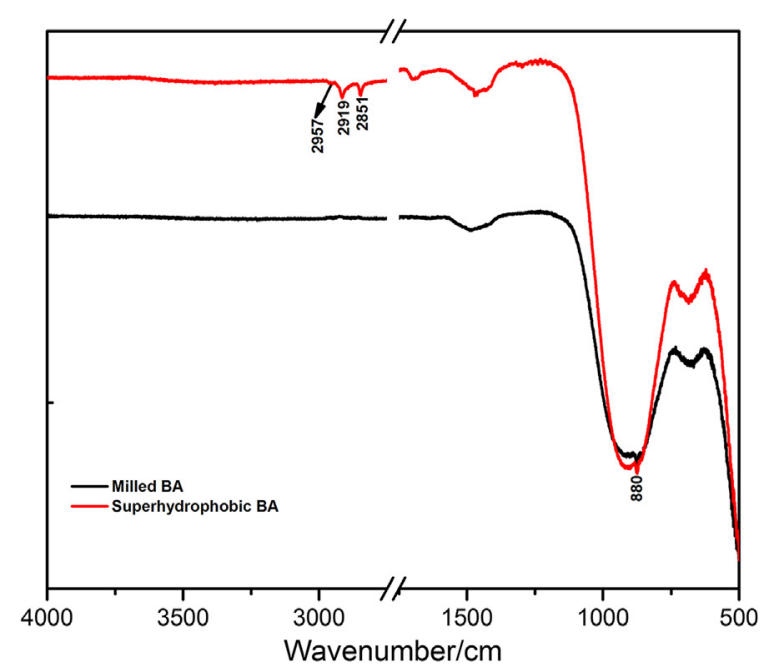

Fig. 6. FTIR spectra of the milling slag and coated slag.

organic coating on continuously graded particle could be roughly calculated using:

$d=\frac{V_{S A}}{S_{\text {slag }}}=\frac{\frac{m_{S A}}{\rho_{S A}}}{m_{\text {slag }} \times B E T_{\text {slag }}}$

where $d$ is the layer thickness of the stearic acid on the slag surface, $\mathrm{V}$ is the total volume of the stearic acid addition, $\mathrm{S}$ is the total surface of the slag powder, $m_{\mathrm{SA}}(\mathrm{g})$ is the mass of the stearic acid and $\rho_{\mathrm{SA}}\left(\mathrm{g} / \mathrm{cm}^{3}\right)$ is the density of stearic acid, $\mathrm{m}_{\text {slag }}$ is the mass of the slag (g) and $\mathrm{BET}_{\text {slag }}\left(\mathrm{m}^{2} / \mathrm{g}\right)$ is the BET surface area of the slag.

The density of stearic acid used in this study is $0.94 \mathrm{~g} / \mathrm{cm}^{3}$, the BET of the raw slag is $1.811 \mathrm{~m}^{2} / \mathrm{g}$ and the content of SA is $1 \%$. Therefore, using the above formula, the theoretical thickness of the stearic acid coating is derived, yielding $5.9 \mathrm{~nm}$. The thicknesses of the coating observed by TEM image is shown in Fig. 7b, which agrees well with the theoretical values.

\subsubsection{Early age hydration kinetics}

The changes of normalized heat flow at early age for the mixes containing super-hydrophobic slag and ordinary slag are shown in
Fig. 8a. Three major peaks, dissolution of materials, and hydration of $\mathrm{C}_{3} \mathrm{~S}$ and aluminate phase, and further hydration of remaining aluminate phases can be distinguished. The third peak corresponds to the depletion of the calcium sulphate phases, attributing to a second aluminate reaction that leads to the formation of AFm (aluminium iron mono-) phase [37]. As the used cement (CEM III/A) contains also blast furnace slag, the reference sample presents similar peak pattern with the mixed ones. It should be noted that with the increasing amount of slag replacement, this peak becomes more evident in comparison with the first peak, which is attributed to the enhanced rate of formation of AFm phases [25,26]. As shown in Fig. 1 (a) and (b), after the milling procedure, the shape of the slag remains similar and the change of particle sizes is not significant, which might be attributed to the relatively short milling duration. Therefore, the differences between the original slag and treated slag can be attributed to the coating of the stearic acid.

It is seen that the addition of both super-hydrophobic slag and raw slag does not affect the position of the first peak, indicating no influence on the hydration process of the mixed cement. However, the second peak slightly shifts to later locations, distributing in the range $19-21 \mathrm{~h}$. This is confirmed by previous researches $[26,38]$ on the influence of ordinary GGBS powder in Portland cement hydration as the slag reacts slower comparing with the Portland cement. Comparing with the mixtures containing ordinary slag at the same addition amount, mixtures with super-hydrophobic slag present a reduced slope of the acceleration curve, indicating a more mild heat release process. This can be attributed to the steric acid coated on the slag that decreases the contact area with water, which will be helpful to decrease the possibility of micro-cracks generation by the created heat stress during the cement hydration.

The cumulative heat curve is an indication of the hydration degree of the binder. It can be observed from Fig. 8b that the heat release of all the super-hydrophobic slag containing binder is lower than that of the reference samples. This has important implications on early age thermal cracking of concretes. It is seen that although the heat release speed of super-hydrophobic slag is slower than the mixtures containing raw slag at the same addition percentage, the total cumulative heat releases are very similar at the end of the measurement time $(40 \mathrm{~h})$. This can be attributed to the coating characteristics of the ball milling method. Comparing with the wet-chemical method by which the target powders are mixed in the solution of surfactant agent, physical coating

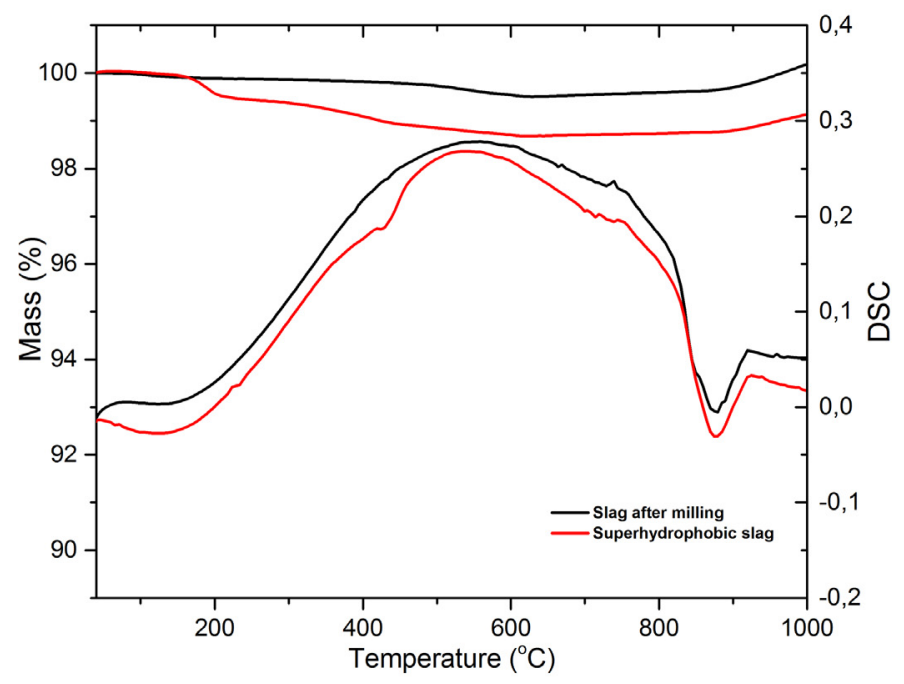

(a)

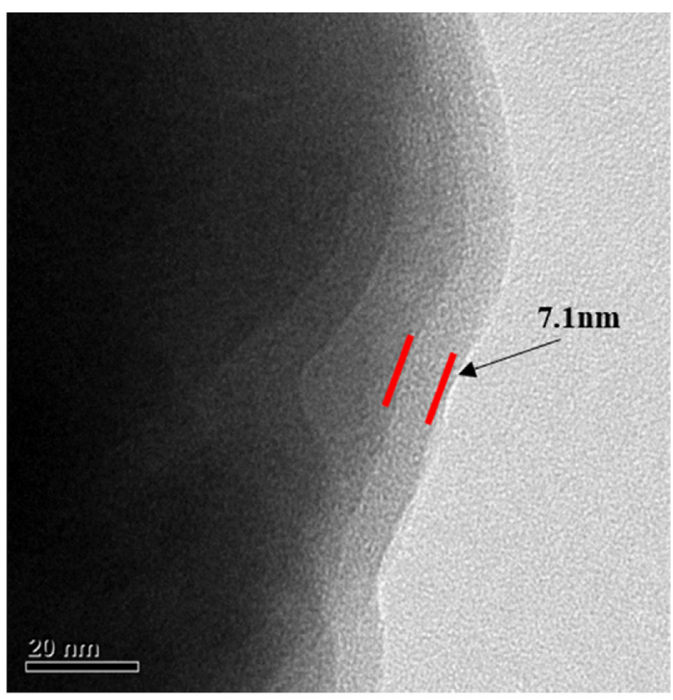

(b)

Fig. 7. (a) TGA/DTA curves of raw and coated slag and (b) TEM image of the treated slag. 

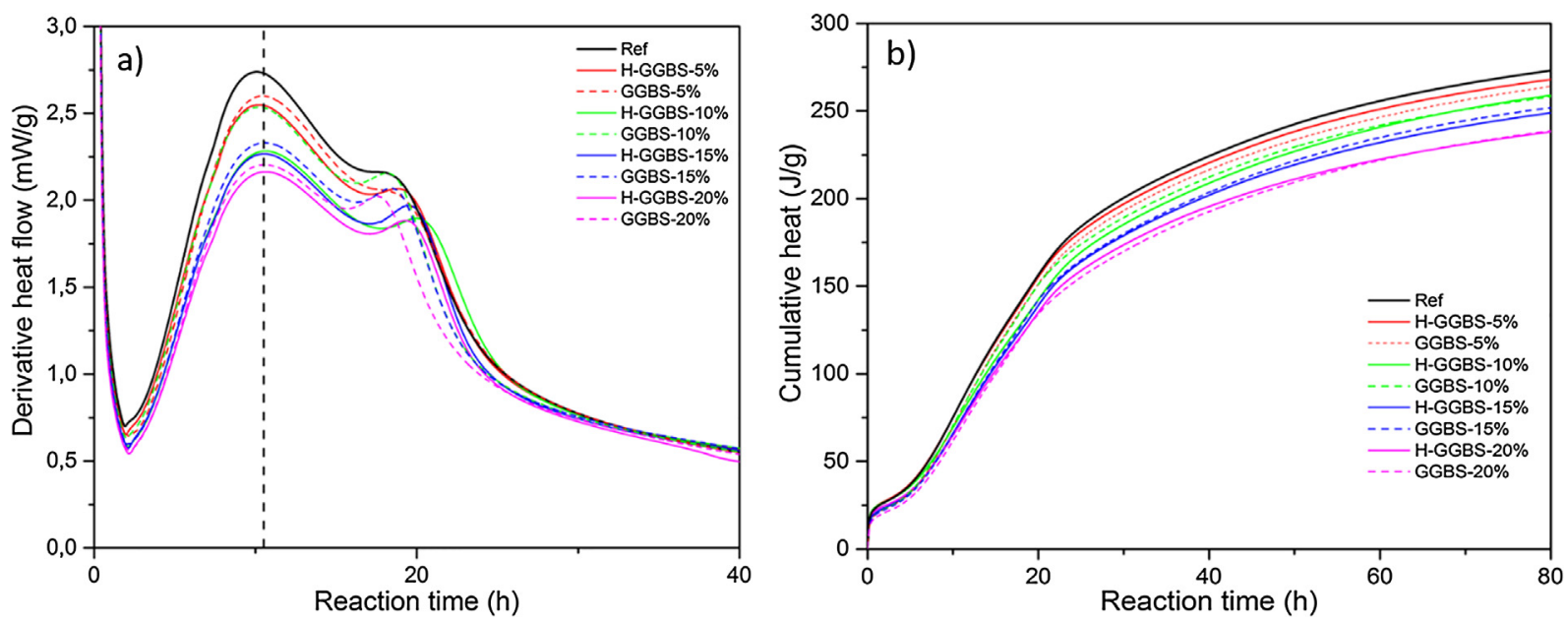

Fig. 8. Normalized heat flow (a) and cumulative heat of hydration (b) of the mixes with different contents of raw and treated slag.

method like ball milling normally presents coating defects especially when the powders present irregular shape. However, as the reactivity of slag is desired for the concrete matrix, the ball milling method is an ideal way to prepare hydrophobic concrete matrix as the reaction potential of the slag is kept, which has been largely reported beneficial for the durability performance of concrete [39]. The slag can be seen as a physical carrier and the ball milling method helps to disperse the stearic acid on its surface.

From the above results, it can be seen that the superhydrophobic slag presents similar role in the hydration process as the uncoated slag. This can be explained by the "imperfect" distribution of stearic acid on the surface of slag through the ball milling method. As can be seen from Fig. 1, the slag presents irregular shape with sharp edges that are difficult to be fully covered during the physical milling process. Therefore, these uncovered points and surface still have the reaction ability with the portlandite resulting from the cement hydration. The slag plays a role as carrier of stearic acid into the lightweight concrete which provides hydrophobic property and meanwhile still keeps the reaction activity.

\subsubsection{Fresh property of the lightweight concrete}

The fresh behaviour of the concrete samples is displayed in Table 2 and an example picture is shown in Fig. 9a. It can be observed that increasing the cement replacement with the superhydrophobic GGBS (H-GBBS) slightly decreases the fresh mix density. In overall, all the H-GGBS contained mixtures show excellent workability. The reference mixture shows the lowest workability and falls under the flow class F3, while M5 to M20 fall under flow class SF1 till SF3 according to self-compacting concrete guideline [30]. Increasing the super-hydrophobic GGBS content clearly leads to an improved workability. The hydrophobicity of the GGBS results in more water flowing freely in the mixture, therefore enhancing the flowability of the mixture. This is different from the reported work [11] in which the addition of the super

Table 2

Fresh properties of the concrete mixtures.

\begin{tabular}{lll}
\hline Mix & Apparent Density $\left(\mathrm{kg} / \mathrm{m}^{3}\right)$ & Flow ability $(\mathrm{cm})$ \\
\hline M0 & 1429.6 & 44 \\
M5 & 1392.4 & 64 \\
M10 & 1366.3 & 70 \\
M20 & 1352.8 & 81 \\
M20 & 1322.3 & 96 \\
\hline
\end{tabular}

hydrophobic powder will decrease the flowability of the concrete. This can be explained by the different natures of the powders. Compared with the very porous paper sludge ash they used, the GGBS used here is rather non-porous, as shown in Fig. 1. So the addition of paper sludge ash will need more water to fill in their pores. The density is slightly decreased with the increase of the addition of super-hydrophobic GGBS that is in line with the flowability changes. As the water is hardly absorbed by the superhydrophobic powder, more free water will move into the cement paste, resulting the increase of the volume of the overall packing system.

\subsubsection{Mechanical properties of the lightweight concrete}

The compressive and flexural strength of the developed lightweight concrete are presented in Fig. 10a and b, and the cross section of a hardened concrete is shown in Fig. 9b. The results show that the compressive strength decreases with the addition of the super-hydrophobic GGBS at the early age of $1 \mathrm{~d}$ and $7 \mathrm{~d}$. This is attributed to the slow reactivity of GGBS, with the largest reduction of $28.9 \%$ and $15.5 \%$ for M20 at $1 \mathrm{~d}$ and $7 \mathrm{~d}$ respectively, compared to the reference. However, the reduction in strength becomes much less prominent at later age. At 28d, mixtures M5 and M10 show higher strength than the reference. For the samples with a 15\% and 20\% H-GGBS replacement, the compressive strength decreases to 28.68 and $24.35 \mathrm{MPa}$, which nevertheless is still $98.5 \%$ and $83.6 \%$ of the reference. A similar pattern can also be found in the development of flexural strength, where the superior strength was observed in the reference sample at $1 \mathrm{~d}$ and $7 \mathrm{~d}$. At 28d, mixtures with $5 \%$ and $10 \% \mathrm{H}-\mathrm{GGBS}$ replacement present a flexural strength of $4.52 \mathrm{MPa}$ and $4.5 \mathrm{MPa}$, respectively, higher than the reference of $4.47 \mathrm{MPa}$. For the samples with a $15 \%$ and $20 \%$ S-GGBS replacement, the flexural strength decreases to 4.35 and $3.89 \mathrm{MPa}$, which is $97.3 \%$ and $87 \%$ of the reference, respectively.

The observed phenomena can be partly explained by the continuous reaction of the H-GGBS with the produced portlandite $[25,40]$. The higher mechanical performance of samples containing H-GGBS can be explained by the microstructure refinement of the lightweight concrete by the super-hydrophobic powder. As can be seen from Fig. 11, comparing with the reference, the H-GGBS contained lightweight concrete yields more needle like structure, attributed to ettringite, and the needle-like structure increases with the addition amount of H-GGBS. It has been reported this cross-linked structure is helpful for dispersing the load on cementitious materials. However, it should also be noted that even at 


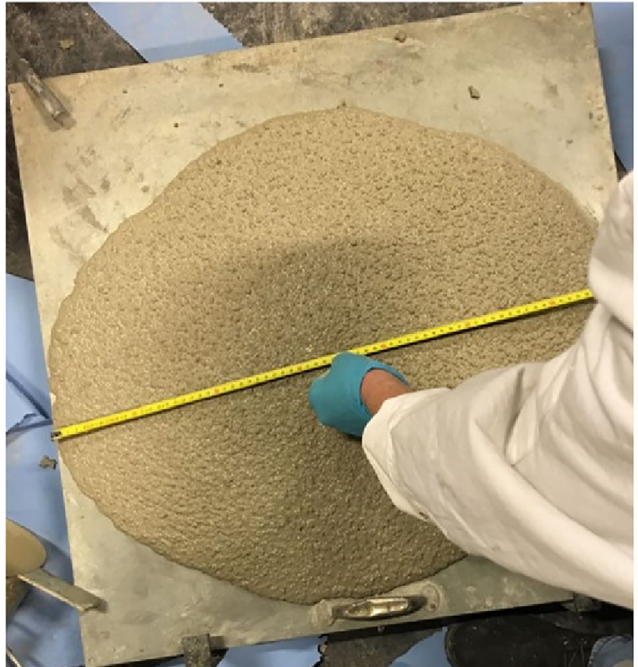

a)

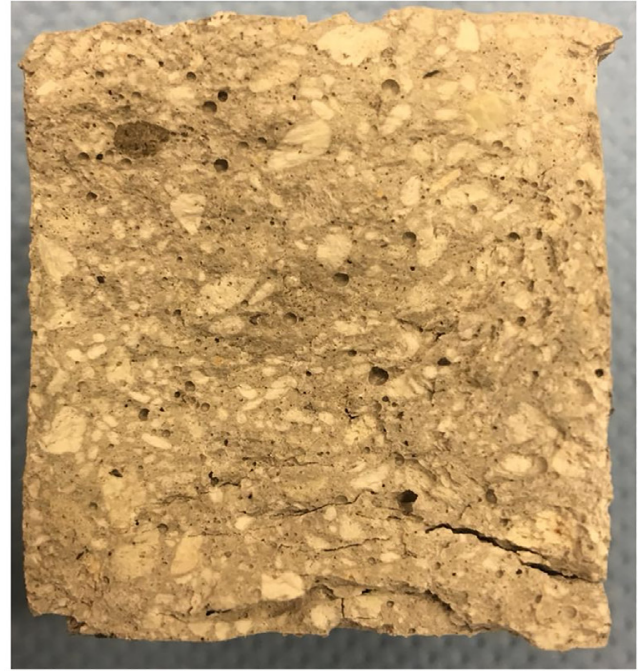

b)

Fig. 9. Picture of the produced lightweight aggregates concrete: (a) fresh state; (b) hardened state).
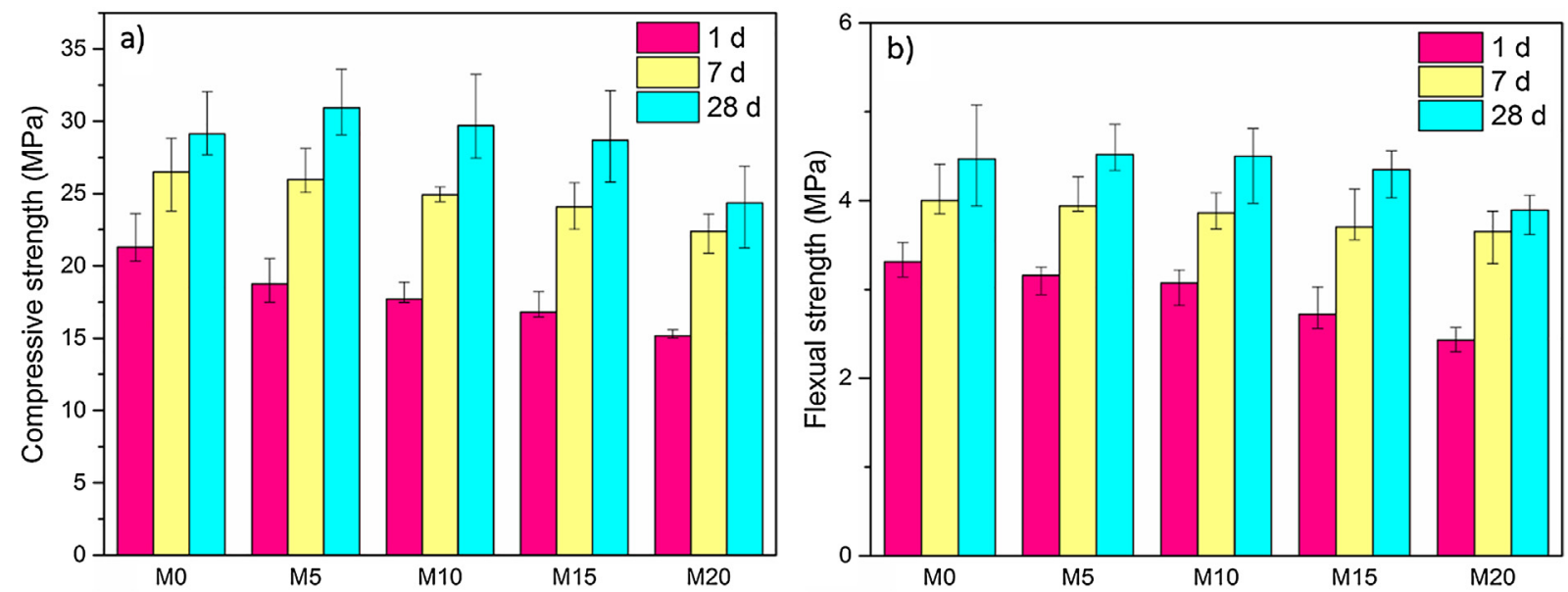

Fig. 10. (a) Compressive and (b) flexural strength of developed lightweight concrete.
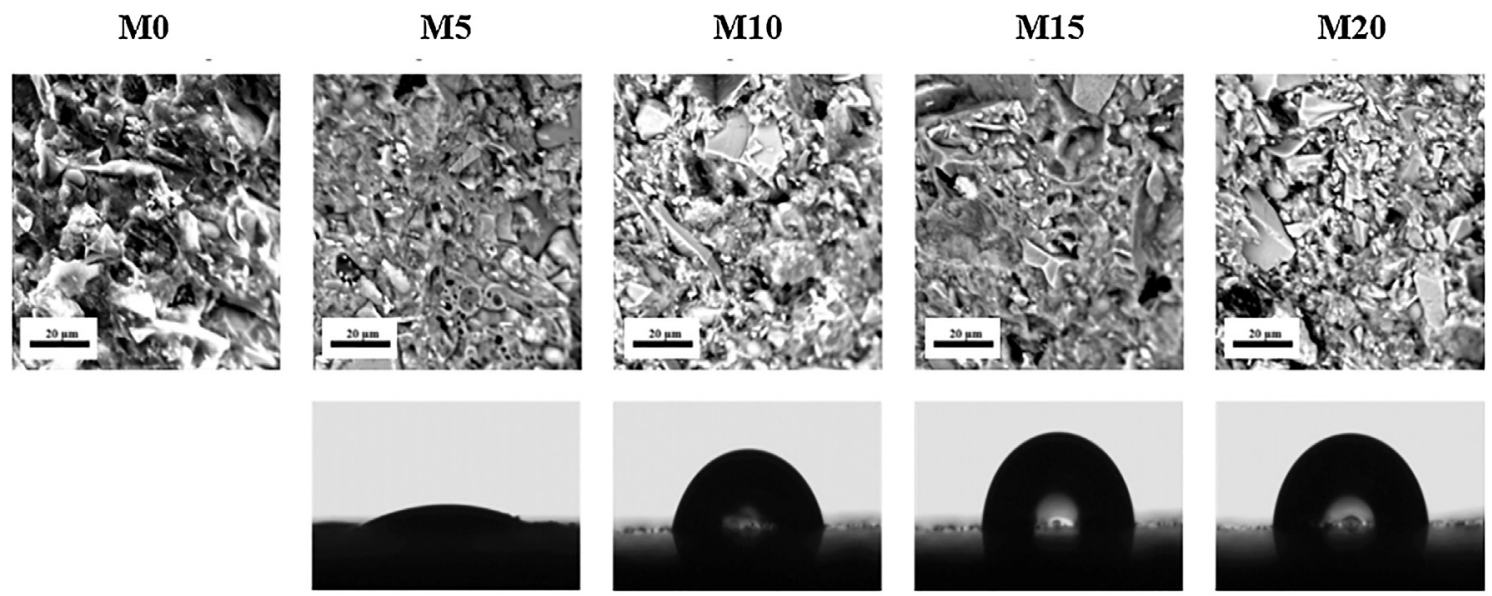

Fig. 11. The micro-structure (top) and water contact angle (bottom) of the hydrophobic lightweight concrete. 
$28 \mathrm{~d}$, the $20 \%$ replacement samples still present the lowest mechanical performance. This is in line with the fresh property changes. With the increasing addition of H-GGBS, more free water becomes available, which creates more capillary pores. As the mechanical performance is primarily governed by the porosity of paste matrix, decrease of mechanical property is resulted.

The hydrophobic performance and microstructure of the superhydrophobic slag modified samples are evaluated in the present study by determining the water contact angle and scanning electron microscopy (SEM) images of the developed lightweight concretes, respectively. The SEM images of the super-hydrophobic slag modified lightweight concrete and the reference sample are shown in Fig. 11 (top). The water contact angles of the lightweight concrete are shown in Fig. 11 (bottom). It is shown from the SEM images that the $5 \%$ and $10 \%$ replacement samples present a denser structure. With the increase of the addition amount of superhydrophobic GGBS, the lightweight concrete presents more pores. For example, at $20 \%$ addition of $\mathrm{HH}$ H-GGBS, pores larger than $20 \mu \mathrm{m}$ are easily observed. This is consistent with the flowability increase and density decrease trend (see Section 3.4). The increasing amount of super-hydrophobic slag will result in more relative free water, which increases the $\mathrm{w} / \mathrm{c}$ ratio and consequently more pores.

It is found that the hydrophobic performance of the hydrophobic lightweight concrete increases from $5 \%$ addition to $10 \%$ addition of the super-hydrophobic GGBS, with the water contact angle increasing from $26^{\circ}$ to $87^{\circ}$ which can be attributed to the increase of the hydrophobic medium dispersion in the concrete. The water contact angle increases to $92^{\circ}$ in the case of M15. However, the water contact angle remains similar, at $91.5^{\circ}$, when $20 \%$ replacement of H-GGBS is applied. This is attributed to the simultaneous effect of the application of hydrophobic agent and increased porosity, as the water resistance ability of the superhydrophobic lightweight concrete is determined by both the dosed hydrophobic agent and the porosity of the concrete itself. With a larger porosity, the water will be more easily penetrating into the concrete matrix.

\subsubsection{Water absorption and chloride diffusion}

The capillary water absorption results are exhibited in Fig. 12. The addition of the super-hydrophobic GGBS significantly decreases the capillary water absorption of the lightweight concrete. At $5 \%$ replacement, the water absorption is reduced by over $60 \%$ and $20 \%$ H-GGBS addition reduces the water absorption by

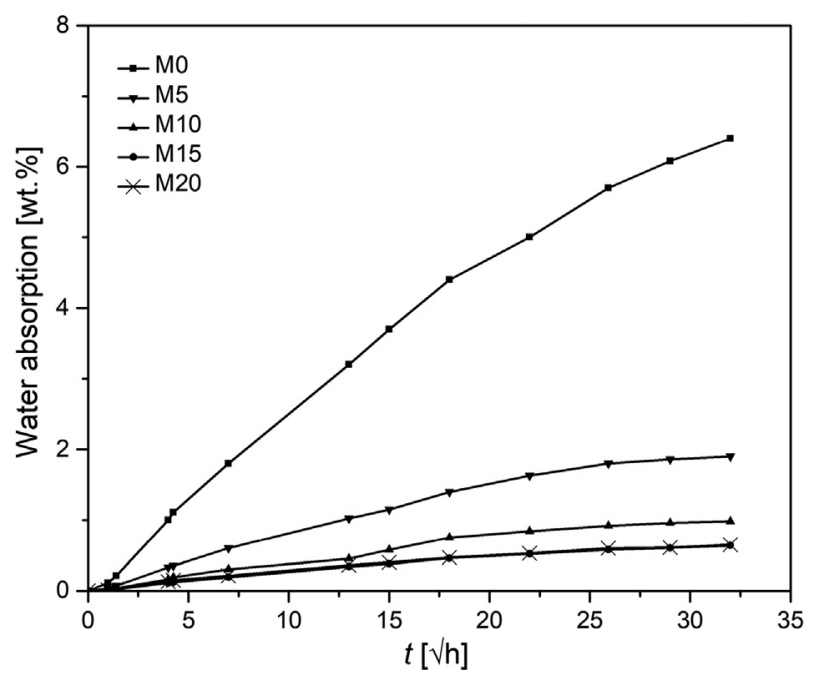

Fig. 12. Capillary water absorption of the lightweight concrete.

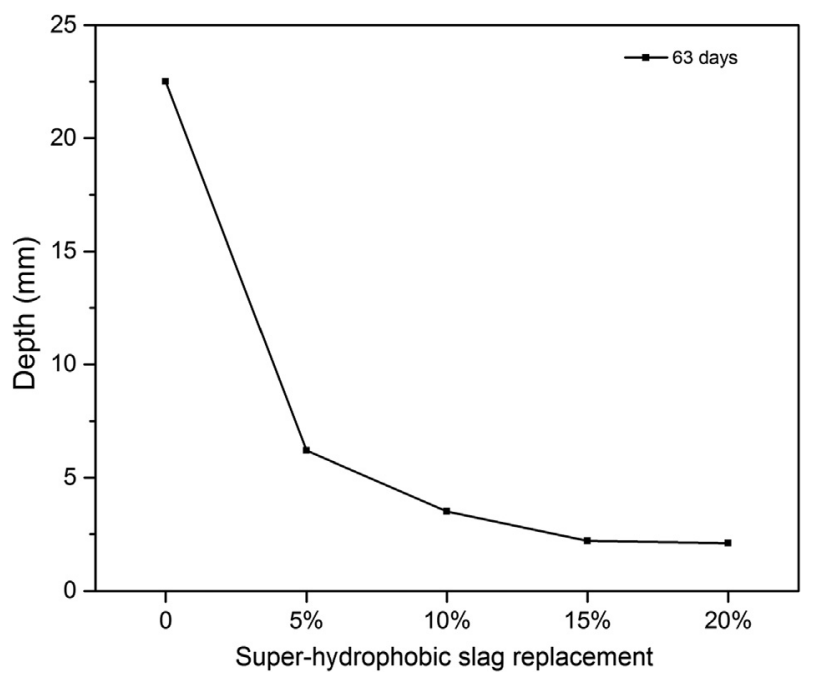

Fig. 13. Chloride penetration depth.

almost 90\%. The 15\% replacement and 20\% replacement present very similar water absorption resistance, which suggests $15 \%$ addition of the super-hydrophobic slag reaches the optimal performance and further adding the H-GGBS shows no effect anymore. This is in line with the other performances as presented in the previous sections. With the increase of the super-hydrophobic slag addition, more free water will be available, which leads to a larger porosity. Even though the super-hydrophobic GGBS increases the water resistance, the higher porosity promotes an easier penetration by water. Capillary suction is an unsaturated transport process by means of capillary forces, related with the surface tension $(\sigma)$ of the wetting liquid and its contact angle $(\theta)$ with a pore of a radius ( $r$ ), as shown in Eq. (2) [40]. When $\theta$ is smaller than $90^{\circ}$, a molecular attraction between the liquid and substrate occurs, accompanied by a capillary rise and a concave meniscus. The superhydrophobic GGBS increases the contact angle above $90^{\circ}$ by forming a water repellent lining in the pore structure of the lightweight concrete. Therefore, it builds a hydrophobic barrier against capillary suction and in turn efficiently decrease the water absorption.

$\Delta P=\frac{2 \sigma \cos \theta}{r}$

Fig. 13 shows the chloride penetration depth after 63 days' exposure to $\mathrm{NaCl}$ solution. It is clear that the super-hydrophobic slag strongly enhances the chloride resistance of the lightweight concrete. The chloride penetration depth at 63 days is reduced by about $90 \%$ for the lightweight concrete with $15 \%$ of superhydrophobic slag, compared to the reference concrete. The application of slag has been reported to be beneficial for reducing the chloride transport in concrete in long term. This can be explained by the pore structure refinement of concrete and more $\mathrm{C}-\mathrm{S}$-H gel generated resulting from the reaction between slag and portlandite that increases the chloride ions binding capacity and also complexes the diffusing route $[41,42]$. Nevertheless, at early ages (i.e. up to 63 days in the present study), the decrease of chloride transport can be mainly due to the hydrophobic effect of the superhydrophobic slag due to the latent reactivity of slag. This is confirmed by the results of water absorption test and hydrophobic performance test. As most of concrete structures are unsaturated during the service and the ingress of water together with aggressive materials is mainly controlled by capillary absorption. The addition of super-hydrophobic GGBS builds up a barrier against the water penetration as it decreases the surface tension of the pore structure of the lightweight aggregates concrete. Therefore, 
the aggressive ions contained in the water will also be slowed down. As the water penetration and chloride transport is relevant to various degradation mechanisms, its reduction proves well the enhanced durability of concrete structures $[11,43,44]$.

\section{Conclusions}

In this study, a reactive super-hydrophobic agent is synthesized employing ball milling method applying ground granulated blast furnace slag as carrier for stearic acid. The influences of milling time, stearic acid addition and milling speed on the hydrophobic behaviour of the treated slag are investigated. The coating mechanism of the stearic acid on the GGBS is discussed. Then the influences of the super-hydrophobic GGBS on the properties of lightweight aggregates concrete, including workability, fresh density, compressive strength, hydrophobicity, capillary water absorption and long-term chloride diffusion are investigated. Base on the present results, the following conclusions can be reached:

1. The hydrophobicity of the slag reaches the maximum at $1 \mathrm{wt} \%$ of stearic acid addition amount. With the increase of the milling time from $10 \mathrm{~min}$ to $30 \mathrm{~min}$, the water contact angle of the GGBS increases due to the efficient dispersing of the stearic acid. A longer time (60 $\mathrm{min})$ shows a decrease in hydrophobicity due to the cutting of the chains of stearic acid. A rotation speed of $100 \mathrm{rpm}$ is the optimal rate to prepare the superhydrophobic slag. The coating process is a physical process, confirmed by the phase and potential reaction group analysis using XRD, XPS and FTIR.

2. The addition of super-hydrophobic slag powder strongly improves the flowability of the lightweight aggregate concrete while slightly reduces the density. The addition of superhydrophobic slag slightly reduces the early age compressive strength, but shows enhancement to 28-day strength up to an addition level of $10 \%$ by mass.

3. The addition of super-hydrophobic slag turns the hydrophilic lightweight concrete to hydrophobic. With an addition of $15 \%$ super-hydrophobic GGBS, the designed lightweight concrete presents the best hydrophobic performance, showing a water contact angle of $92^{\circ}$.

4. The application of the super-hydrophobic slag significantly contributes to an enhanced durability. With a dosage of $15 \%$, the capillary water absorption and long-term chloride penetration depth reduce up to about $90 \%$.

\section{Conflict of interest}

None.

\section{Acknowledgements}

The financial support by STW-foundation (Project No. 10979) and Chinese Scholarship Council (201606950006) are acknowledged. The authors gratefully thank Mr. Dylan for the TEM experiment and Mr. Feng is thanked for the kind discussion.

\section{References}

[1] Q.L. Yu, P. Spiesz, H.J.H. Brouwers, Development of cement-based lightweight composites-Part 1: mix design methodology and hardened properties, Cem. Concr. Compos. 44 (2013) 17-29.

[2] M.H. Zhang, O.E. Gjvorv, Mechanical properties of high-strength lightweight concrete, Mater. J. 88 (1991) 240-247.

[3] P. Spiesz, Q.L. Yu, H.J.H. Brouwers, Development of cement-based lightweight composites-Part 2: Durability-related properties, Cem. Concr. Compos. 44 (2013) 30-40.

[4] Q.L. Yu, H.J.H. Brouwers, Development of a self-compacting gypsum-based lightweight composite, Cem. Concr. Compos. 34 (2012) 1033-1043.
[5] Q.L. Yu, P. Spiesz, H.J.H. Brouwers, Ultra-lightweight concrete: conceptual design and performance evaluation. Cem. Concr. Compos. 61 (2015) 18-28.

[6] M.N. Haque, H. Al-Khaiat, O. Kayali, Strength and durability of lightweight concrete, Cem. Concr. Compos. 26 (2004) 307-314.

[7] H. Du, S. Du, X. Liu, Effect of nano-silica on the mechanical and transport properties of lightweight concrete, Constr. Build. Mater. 82 (2015) 114-122.

[8] Z.Y. Qu, Q.L. Yu, H.J.H. Brouwers, Relationship between the particle size and dosage of LDHs and concrete resistance against chloride ingress, Cem. Concr. Res. 105 (2018) 81-90.

[9] R. Yu, P. Spiesz, H.J.H. Brouwers, Effect of nano-silica on the hydration and microstructure development of Ultra-High Performance Concrete (UHPC) with a low binder amount, Constr. Build. Mater. 65 (2014) 140-150.

[10] F. Sanchez, K. Sobolev, Nanotechnology in concrete-a review, Constr. Build. Mater. 24 (2010) 2060-2071.

[11] H.S. Wong, R. Barakat, A. Alhilali, M. Saleh, C.R. Cheeseman, Hydrophobic concrete using waste paper sludge ash, Cem. Concr. Res. 70 (2015) 9-20.

[12] S. Grumbein, D. Minev, M. Tallawi, K. Boettcher, F. Prade, F. Pfeiffer, C.U. Grosse, O. Lieleg, Hydrophobic Properties of Biofilm-Enriched Hybrid Mortar, Adv. Mater. 28 (2016) 8138-8143.

[13] F. Tittarelli, Oxygen diffusion through hydrophobic cement-based materials, Cem. Concr. Res. 39 (2009) 924-928.

[14] J. De Vries, R.B. Polder, Hydrophobic treatment of concrete, Constr. Build, Mater. 11 (1997) 259-265.

[15] N. Yao, P. Zhang, L. Song, M. Kang, Z. Lu, R. Zheng, Stearic acid coating on circulating fluidized bed combustion fly ashes and its effect on the mechanical performance of polymer composites, Appl. Surf. Sci. 279 (2013) 109-115.

[16] C. Spathi, N. Young, J.Y.Y. Heng, L.J.M. Vandeperre, C.R. Cheeseman, A simple method for preparing super-hydrophobic powder from paper sludge ash, Mater. Lett. 142 (2015) 80-83.

[17] W. Liu, Z. Xie, X. Yang, Y. Wu, C. Jia, T. Bo, L. Wang, Surface Modification Mechanism of Stearic Acid to Zirconia Powders Induced by Ball Milling for Water-Based Injection Molding, J. Am. Ceram. Soc. 94 (2011) 1327-1330.

[18] M.M. Alonso, M. Palacios, F. Puertas, Compatibility between polycarboxylatebased admixtures and blended-cement pastes, Cem. Concr. Compos. 35 (2013) $151-162$.

[19] L. Feng, H. Zhang, P. Mao, Y. Wang, Y. Ge, Superhydrophobic alumina surface based on stearic acid modification, Appl. Surf. Sci. 257 (2011) 3959-3963.

[20] T. Tsuzuki, K. Pethick, P.G. McCormick, Synthesis of CaCO3 nanoparticles by mechanochemical processing, J. Nanoparticle Res. 2 (2000) 375-380.

[21] M. Fuji, N. Maruzuka, J. Yoshimori, T. Takei, T. Watanabe, M. Chikazawa, K. Tanabe, K. Mitsuhashi, Surface active sites introduced onto calcium carbonate powder by a new surface preparation process, Adv. Powder Technol. 11 (2000) 199-210.

[22] Z. Cao, M. Daly, L. Clémence, L.M. Geever, I. Major, C.L. Higginbotham, D.M. Devine, Chemical surface modification of calcium carbonate particles with stearic acid using different treating methods, Appl. Surf. Sci. 378 (2016) 320329.

[23] R. Hong, T. Pan, J. Qian, H. Li, Synthesis and surface modification of ZnO nanoparticles, Chem. Eng. J. 119 (2006) 71-81.

[24] W. Liu, Z.P. Xie, L.L. Zhang, X.F. Yang, Debinding behaviors and mechanism of injection molded $\mathrm{ZrO} 2$ ceramics using kerosene as solvents, Key Eng. Mater. Trans. Tech. Publ. (2012) 431-434.

[25] B. Yuan, Q.L. Yu, H.J.H. Brouwers, Reaction kinetics, reaction products and compressive strength of ternary activators activated slag designed by Taguchi method, Mater. Des. 86 (2015) 878-886.

[26] S. Kourounis, S. Tsivilis, P.E. Tsakiridis, G.D. Papadimitriou, Z. Tsibouki, Properties and hydration of blended cements with steelmaking slag, Cem. Concr. Res. 37 (2007) 815-822.

[27] V. Kocaba, E. Gallucci, K.L. Scrivener, Methods for determination of degree of reaction of slag in blended cement pastes, Cem. Concr. Res. 42 (2012) 511-525.

[28] G. De Schutter, Hydration and temperature development of concrete made with blast-furnace slag cement, Cem. Concr. Res. 29 (1999) 143-149.

[29] C. Giosuè, Q.L. Yu, M.L. Ruello, F. Tittarelli, H.J.H. Brouwers, Effect of pore structure on the performance of photocatalytic lightweight lime-based finishing mortar, Constr. Build. Mater. 171 (2018) 232-242.

[30] G. Hüsken, H.J.H. Brouwers, A new mix design concept for earth-moist concrete: A theoretical and experimental study, Cem. Concr. Res. 38 (2008) $1246-1259$.

[31] B.S. EN, 12350-2, “Testing fresh concrete-Part 2: Slump test," Eur. Comm. Stand. (2009).

[32] T.S. EN, 196-1. Methods of testing cement-Part 1: Determination of strength, Eur. Comm. Stand. 26 (2005).

[33] B.S. EN, 480-5: 2005 Admixtures for concrete, mortar and grout, Test Methods. Determ. Capill. Absorpt. (n.d.).

[34] N.T. Build, 443, Concrete, hardened: accelerated chloride penetration, Nord. Method. (1995).

[35] S. Wang, L. Jiang, Definition of superhydrophobic states, Adv. Mater. 19 (2007) 3423-3424.

[36] T. Arbatan, X. Fang, W. Shen, Superhydrophobic and oleophilic calcium carbonate powder as a selective oil sorbent with potential use in oil spill clean-ups, Chem. Eng. J. 166 (2011) 787-791.

[37] R. Tixier, R. Devaguptapu, B. Mobasher, The effect of copper slag on the hydration and mechanical properties of cementitious mixtures, Cem. Concr. Res. 27 (1997) 1569-1580.

[38] B. Singh, A.J. Majumdar, The hydration of calcium dialuminate and its mixtures containing slag, Cem. Concr. Res. 22 (1992) 1019-1026. 
[39] C. Pellegrino, V. Gaddo, Mechanical and durability characteristics of concrete containing EAF slag as aggregate, Cem. Concr. Compos. 31 (2009) 663-671.

[40] I. Pane, W. Hansen, Investigation of blended cement hydration by isothermal calorimetry and thermal analysis, Cem. Concr. Res. 35 (2005) 1155-1164.

[41] F. Leng, N. Feng X. Lu, An experimental study on the properties of resistance to diffusion of chloride ions of fly ash and blast furnace slag concrete, Cem. Concr. Res. 30 (2000) 989-992.
[42] H.-W. Song, V. Saraswathy, Studies on the corrosion resistance of reinforced steel in concrete with ground granulated blast-furnace slag-an overview, J. Hazard. Mater. 138 (2006) 226-233.

[43] P. Spiesz, M.M. Ballari, H.J.H. Brouwers, RCM: a new model accounting for the non-linear chloride binding isotherm and the non-equilibrium conditions between the free-and bound-chloride concentrations, Constr. Build. Mater. 27 (2012) 293-304.

[44] P. Spiesz, H.J.H. Brouwers, Influence of the applied voltage on the Rapid Chloride Migration (RCM) test, Cem. Concr. Res. 42 (2012) 1072-1082. 